7. Reprod. Fert. (1974) 39, 365-371

\title{
INTERSEXUALITY IN A COCKER SPANIEL DOG
}

\author{
ANNE R. DAIN \\ Agricultural Research Council Institute of Animal Physiology, Babraham, Cambridge
}

(Received 5th December 1973)

\begin{abstract}
Summary. An intersex Cocker spaniel dog is described in which the genotype was female but the gonads were testes and in which both Wolffian and Müllerian structures were found. The external genitalia were masculinized. The condition of this animal is discussed and compared with that of other intersex dogs that have been reported. It is suggested that the deformities found in these animals are consistent with a progressive activation of a sequence of male-determining genes. The abnormality is imputed to a failure of the normal controlling mechanisms for female development.
\end{abstract}

\section{INTRODUCTION}

Several accounts have been given of intersex dogs (Hernaman-Johnson, 1935; Phillips, Brief, Sutton \& Mills, 1939; Stunzi \& Stunzi, 1950; Lee \& Allam, 1952; Lawrence \& Meisels, 1952; Morris, 1952; Brodey, Martin \& Lee, 1954; Walker, 1961), but the genetic sex of these animals was unknown.

This paper presents the anatomical and chromosomal findings for a further intersex dog and relates these findings to those of previous authors in the same field.

\section{METHODS}

Chromosome preparations were made from whole blood by a modification of the method of Basrur \& Gilman (1964) and from skin fibroblasts by a modification of the method of Hyman \& Poulding (1972). In both cases, the specimens were taken from the living animal. Histological sections of the gonads, the internal genitalia and the urogenital sinus were prepared, and were stained with haematoxylin and eosin.

\section{OBSERVATIONS}

In October 1972, a Cocker spaniel puppy aged 12 weeks was brought to this Institute for examination. It was one of a litter of four, of which two were dogs and one was a bitch. The puppy was classified as a female at birth, but later proved to have external genitalia of indeterminate sex. The labia of the vulva were fused and displaced forwards onto the abdomen in a position intermediate between the normal location of the vulva in the female and that of the prepuce 
in the male. The sinus underlying the fused labia could not be described as a vagina. There was a small penis measuring approximately $6 \mathrm{~cm}$ which contained an os and which had a hypospadiac urethra.

The dog was killed when it was 11 months old and the internal genitalia were examined. Their appearance is shown diagrammatically in Text-fig. 1. There were two abdominal testes measuring approximately $15 \mathrm{~mm}$ in the long axis: each had a well-developed epididymis, from which the ductus deferens ran posteriorly to end at the prostate gland on the wall of the urethra. Right and left gubernaculae were present. The Müllerian system was represented by oviducts and uterine horns lined by an inactive endometrium which ran from

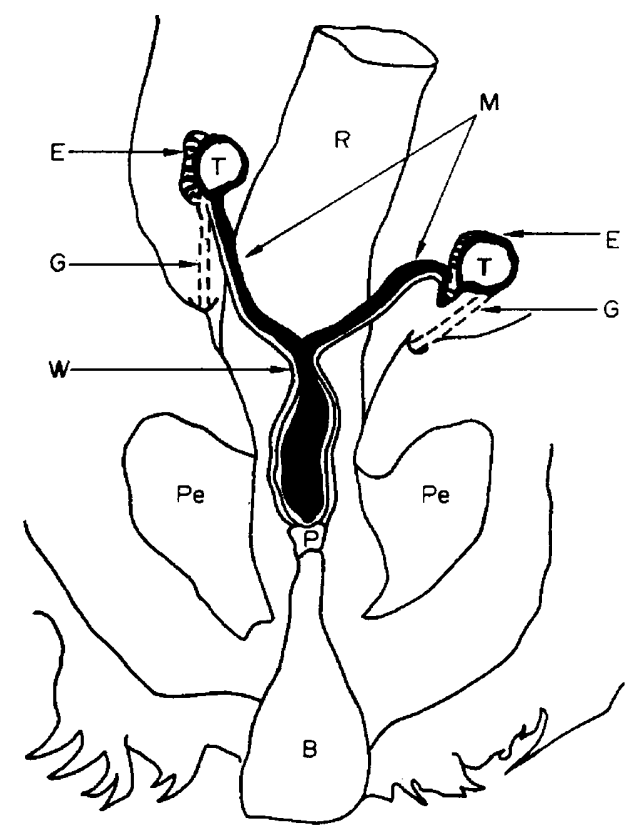

TEXT-FIG. 1. Diagram of the internal genitalia of an intersex dog. B, bladder, folded back on the urethra; E, epididymis; $G$, gubernaculum; $M$, Müllerian derivatives; $P$, prostate; Pe, pelvis; $R$, rectum; $T$, testis; $W$, Wolffian derivatives.

the testes to fuse in the mid-line, where they formed a single tube extending backwards about $5 \mathrm{~cm}$ to end blindly near the neck of the bladder.

Histological sections of this body showed that there was a constriction about $5 \mathrm{~mm}$ caudal to the bifurcation. This constriction may have represented the cervix. The region immediately posterior to it, where the lumen widened, may have represented the Müllerian region of the vagina which was lined with columnar epithelium and had a castrate appearance.

Stained sections of the gonads showed that they both consisted of seminiferous tubules and of interstitial cells which were typical of the testis. There was no sign of spermatogenesis. The tubules appeared to be lined largely by Sertoli cells; a few of these cells, however, had large smooth nuclei and it is possible that they were germ cells. No cells undergoing mitosis were seen. In the inter- 
stitial tissue of the testes, a large number of the cells contained nuclei with dense chromatin bodies which lay against the nuclear membrane. These may have been sex chromatin bodies. Their presence would indicate that many of the gonadal cells were female.

The results of the examination of the chromosomes are set out in Table 1. The normal complement in the dog consists of 78 chromosomes, and the $\mathrm{X}$ chromosomes are large submetacentric chromosomes which are easily distinguishable from the acrocentric autosomes. The $\mathrm{Y}$ chromosome is very small and dense. One hundred blood cells were examined and the chromosomes were counted, but, with the exception of one hypomodal cell in which a fragment of chromatin raised some doubts, all were easily classified as female. Twenty-six skin cells prepared from two primary cultures (cells which grew out directly from the biopsy) were examined and had a female karyotype. Seven cells of the 131 which were examined were found to be hypermodal, with 79 chromosomes. One of these cells may have had three $\mathrm{X}$ chromosomes.

Table 1. An analysis of the chromosome numbers present in the cells of blood and skin from an intersex Cocker spaniel

\begin{tabular}{|c|c|c|c|c|c|c|}
\hline \multirow{2}{*}{ Tissue } & \multicolumn{6}{|c|}{ No. of chromosomes } \\
\hline & $\begin{array}{c}76 \\
\text { and fewer }\end{array}$ & 77 & 78 & 79 & 80 & Total \\
\hline $\begin{array}{c}\text { Blood leucocytes } \\
2.11 .1972 \\
16.11 .1972\end{array}$ & $\begin{array}{r}14 \\
4\end{array}$ & $\begin{array}{l}5 \\
5\end{array}$ & $\begin{array}{l}28 \\
39\end{array}$ & $\begin{array}{l}3 \\
2\end{array}$ & $\begin{array}{l}0 \\
0\end{array}$ & $\begin{array}{l}50 \\
50\end{array}$ \\
\hline $\begin{array}{l}\text { Skin cells } \\
\text { (primary cultures) } \\
2.3 .1973 \\
3.7 .1973\end{array}$ & $\begin{array}{l}3 \\
7\end{array}$ & $\begin{array}{l}0 \\
1\end{array}$ & $\begin{array}{r}2 \\
16\end{array}$ & 2 & & $\begin{array}{r}5 \\
26\end{array}$ \\
\hline
\end{tabular}

\section{DISGUSSION}

No chromosomal abnormalities could be positively identified in this dog, although the proportion of hypermodal cells is high for a young animal. McFeely \& Biggers (1965) also reported a hypermodal cell in their study of twenty-three cells from the first animal in Table 3 and the phenomenon may be akin to that found in freemartin sheep (Bruère, 1967). It is interesting that Hamerton, Dickson, Pollard, Grieves \& Short (1969), in their comprehensive study of intersex goats, did not find a high proportion of hypermodal cells.

The disorder in the genital system of animals such as this helps the understanding of the normal process of sex differentiation. Reliable techniques of chromosome preparation now make it easy to examine the genetic sex of intersex animals. The work of Jost (1970) on the control of sex determination in the embryo and the recent advances in understanding the rôle of the sex chromosomes in mammals assist in attempts to classify the wide variety of intersex abnormalities.

In Table 2, some of the findings of previous authors concerning nine intersex dogs, five of which were Cocker spaniels, have been summarized in order to 


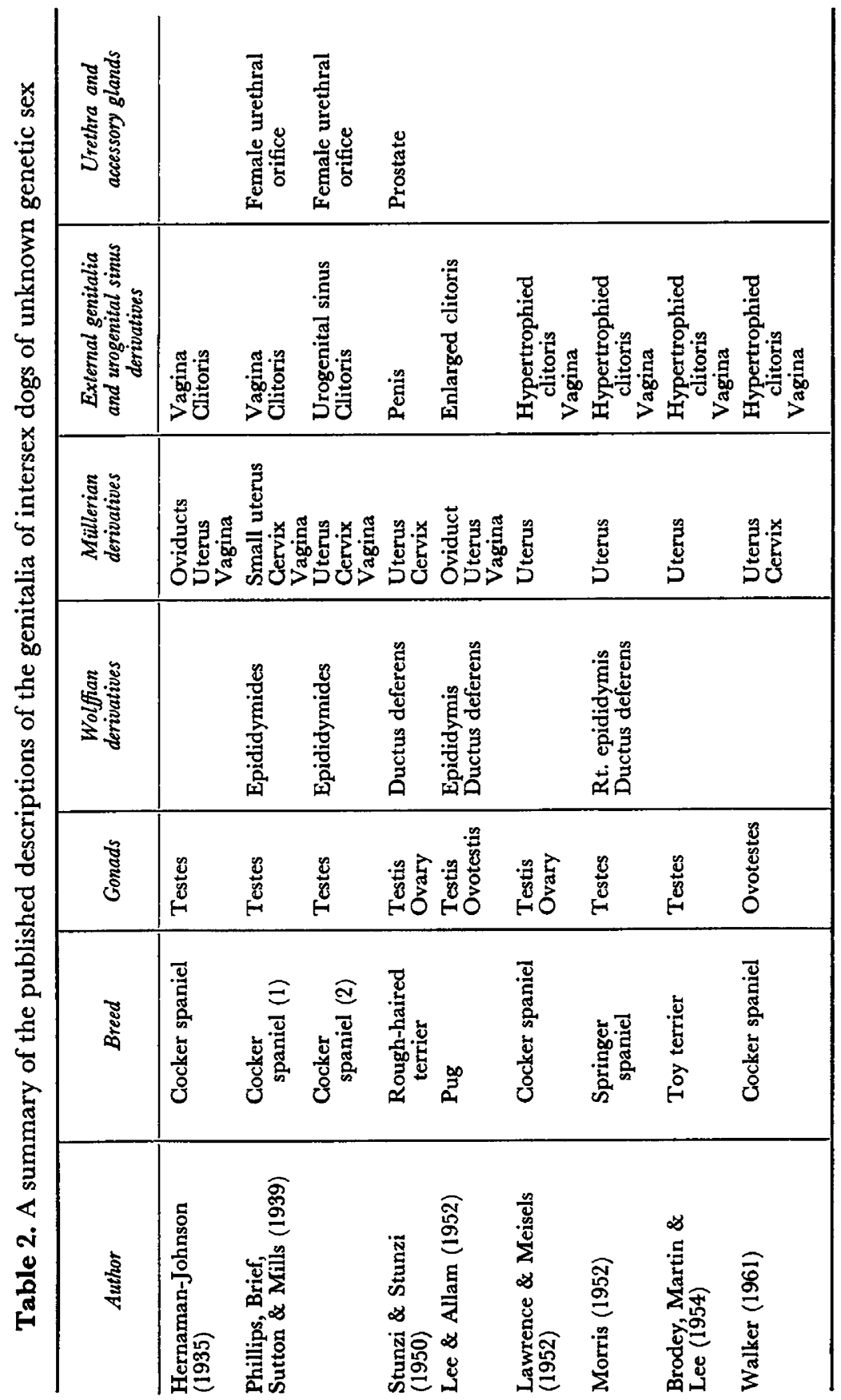


Intersexuality in a spaniel dog

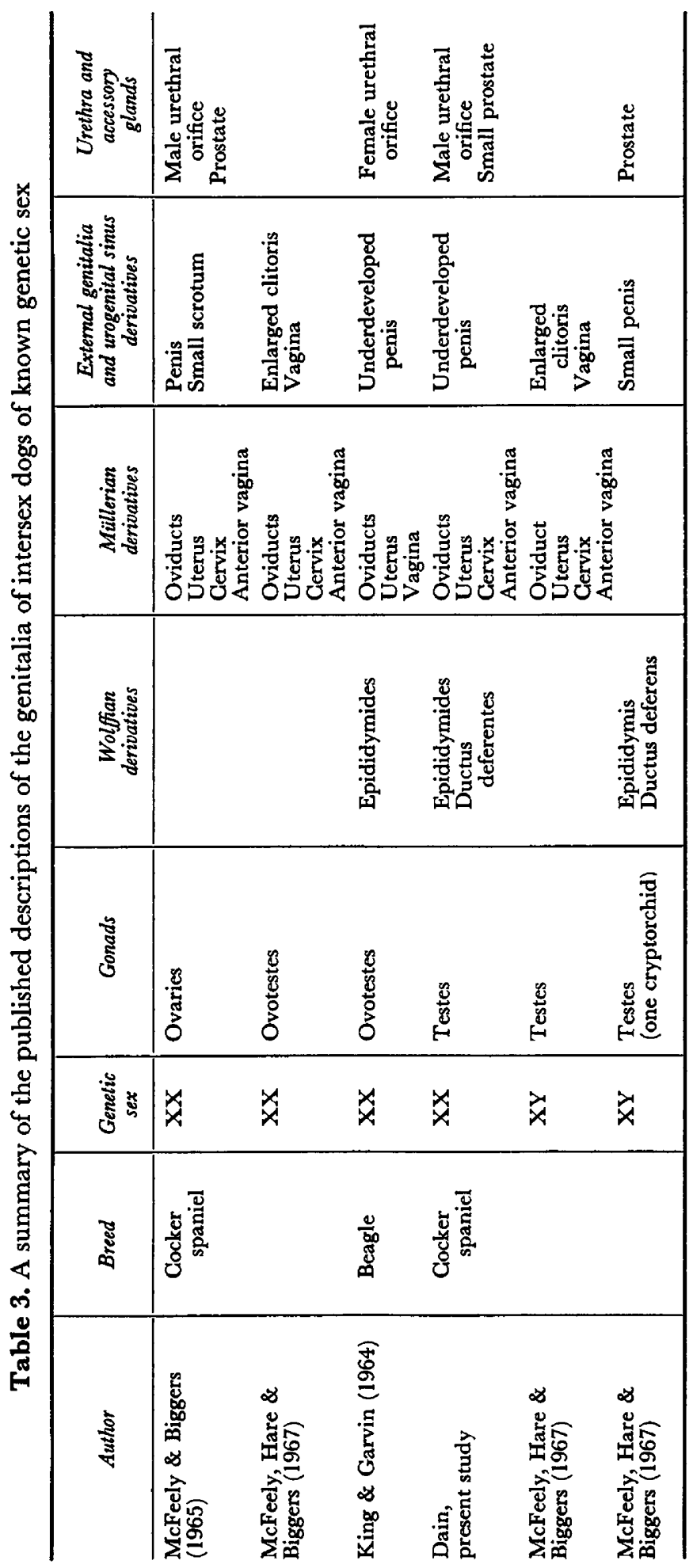


show the consistency of certain features for comparison with six dogs (Table 3) in which the genetic sex was known. Of the dogs for which the genetic sex was reported, four were $\mathrm{XX}$ and two were $\mathrm{XY}$ intersexes. The breed of only three of these dogs was known and two were Cocker spaniels.

The last three genetic females and the first genetic male stand out in the similarity of their development. It is striking that Müllerian derivatives persisted in all of them, irrespective of the gonadal sex. The persistence of the Wolffian derivates appears to have coincided, as the work of Jost (1955) indicates, with the extent to which the gonads developed as testes. On the basis of these observations, an hypothesis is now put forward which develops that of McFeely, Hare \& Biggers (1967). Their theory was based on that of Ohno (1965) of the origin of the $\mathrm{X}$ and $\mathrm{Y}$ chromosomes from an homologous pair of autosomes. They suggested that the $\mathrm{X}$ chromosome contains homologous male-determining genes which can be either repressed or activated. Activation would normally be effected by the $\mathrm{Y}$ chromosome in the male complement, but in the abnormal female genotype also it could be brought about by aberrant autosomal influence. An explanation similar to that of McFeely et al. (1967) was put forward by Hamerton (1968) in his study of the intersex goat.

It appears from the evidence which is presented above and from the records which are summarized in Table 3 that, in these dogs, the Müllerian system of ducts is not suppressed as it would normally be in the presence of a testis. Suppression is known to be mediated by a testicular hormone. In these cases, it may be that the testis produces the hormone but that the tissue of the ducts is not responsive and they therefore persist. Alternatively, the genes controlling the development of a testis, which should be altogether inactive in the normal XX complement may be extensively but not completely functional. Their activity is obviously sufficient to allow development of a normal structure (although it is a sterile one). Androgen production is enough to effect varying degrees of masculinity in the genitalia, but it is suggested that the activation of genes controlling testis development is incomplete, so that the hormone which suppresses the Müllerian system is not produced. The records (Table 3) show that the condition can occur in a testis of male nuclear sex, and this supports the hypothesis of an abnormality in the controlling genes.

The condition is illustrated by the first genetic male in Table 3 and by the last three genetic females. In two of these cases, there may also be incomplete activation of testis determinants. The four animals together provide a graded sequence of activation in the male determinants. In the normal female, of course, none of these determinants is active.

The first and last animals in Table 3 are misfits, but their peculiarities may be explained. The atypical external genitalia of the genetic female could have been caused, as McFeely \& Biggers (1965) point out, by the influence of a masculinizing agent on the fetus in utero. The underdevelopment of the penis of the last genetic male, in which female features were absent, may have been the result of low androgen production which is possibly associated with cryptorchidism.

Androgen hormone studies were not undertaken in the present case, nor for any of the other dogs. Such data might make better sense of the state of mas- 
culinization of the external genitalia which depends on androgen production by the testis (Jost, 1955).

\section{ACKNOWLEDGMENTS}

I am grateful to Mr G. A. Embleton for drawing my attention to this animal, for his help in taking specimens of blood and skin and with the examination of the genitalia. I should also like to thank Dr M. Courot of the Laboratory of Physiology of Reproduction, Nouzilly, France, for his careful help in interpreting the histology of the testis. I am grateful to Mr L. G. Jarvis of this Institute for the histological preparations.

\section{REFERENGES}

BasruR, P. K. \& Gilman, J. P. W. (1964) Blood culture method for the study of bovine chromosomes. Nature, Lond. 204, 1335.

Brodey, R. S., Martin, J. E. \& Lee, D. G. (1954) Male pseudohermaphroditism in a toy terrier. J. Am. vet. med. Ass. 125, 368 .

BRUÈRE, A. N. (1967) Evidence of age aneuploidy in the chromosomes of the sheep. Nature, Lond. 215, 658.

Hamerton, J. L. (1968) Significance of sex chromosome derived heterochromatin in mammals. Nature, Lond. 219, 910.

Hamerton, J. L., Dickson, J. M., Pollard, G. E., Grieves, S. A. \& Short, R. V. (1969) Genetic intersexuality in goats. F. Reprod. Fert., Suppl. 7, 25.

Hernaman-Johnson, K. (1935) Complex hermaphrodism in a cocker. Vet. Rec. 15, 1099.

Hyman, J. H. \& Poulding, R. H. (1972) Culture and preparation of human fibroblasts for chromosome studies. In Animal Tissue Culture, Ch. 7. Ed. G. D. Wasley. Butterworths, London.

Jost, A. (1955) Modalities in the action of gonadal and gonad-stimulating hormones in the foetus. Mem. Soc. Endocr. 4, 237.

Jost, A. (1970) Hormonal factors in the sex differentiation of the mammalian foetus. Phil. Trans. R. Soc. B, $259,119$.

King, N. W. \& Garvin, C. H. (1964) Bilateral hermaphroditism in a dog. F. Am. vet. med. Ass. 145, 997.

Lawrence, J. \& Metsels, R. (1952) A lateral canine hermaphrodite. F. Am. vet. med. Ass. 121, 171.

Lee, D. G. \& Allam, M. W. (1952) True unilateral hermaphroditism in a dog. Vet. Ext. Q. Univ. Pa, $128,142$.

McFeely, R. A. \& Biggers, J. D. (1965) A rare case of female pseudo-hermaphrodism in the dog. Vet. Rec. 77, 696.

McFeely, R. A., HARe, W. C. D. \& Biggers, J. D. (1967) Chromosome studies in 14 cases of intersex in domestic mammals. Cytogenetics, 6, 242.

MorRIs, P. G. D. (1952). Pseudohermaphrodite dog. Br. vet. F. 108, 375.

Ohno, S. (1965) A phylogenetic view of the X chromosome in man. Annls Genét. 8, 3.

Phillips, J. M., Brief, B. J., Sutton, T. S. \& Mills, J. W. (1939) Hermaphroditism. 7. Am. vet. med. Ass. 95, 663.

Stunzi, B. \& Stunzi, H. (1950) Hermaphroditismus versus unilateralis bein Hund mit Blastermoser entertung des rudimentaren Ovars. Schweizer Arch. Teirheilk. 92, 67.

WAlKer, R. G. (1961) Hermaphroditism in a bitch. A case report. Vet. Rec. 73, 670. 